\title{
Gene-environment interactions in severe mental illness
}

\author{
Rudolf Uher ${ }^{1,2,3 *}$ \\ ${ }^{1}$ Department of Psychiatry, Dalhousie University, Halifax, NS, Canada \\ ${ }^{2}$ Department of Psychology and Neuroscience, Dalhousie University, Halifax, NS, Canada \\ ${ }^{3}$ Social, Genetic and Developmental Psychiatry Centre, Institute of Psychiatry, King's College London, London, UK
}

Edited by:

Helen Fisher, King's College London, UK

\section{Reviewed by:}

Silvia Alemany, Universitat de

Barcelona, Spain

Ruud Van Winkel, Maastricht

University, Netherlands

*Correspondence:

Rudolf Uher, Department of

Psychiatry, Dalhousie University, 5909

Veterans' Memorial Lane, Halifax, NS

B3H 2E2, Canada

e-mail: uher@dal.ca
Severe mental illness (SMI) is a broad category that includes schizophrenia, bipolar disorder, and severe depression. Both genetic disposition and environmental exposures play important roles in the development of SMI. Multiple lines of evidence suggest that the roles of genetic and environmental factors depend on each other. Gene-environment interactions may underlie the paradox of strong environmental factors for highly heritable disorders, the low estimates of shared environmental influences in twin studies of SMI, and the heritability gap between twin and molecular heritability estimates. Sons and daughters of parents with SMI are more vulnerable to the effects of prenatal and postnatal environmental exposures, suggesting that the expression of genetic liability depends on environment. In the last decade, gene-environment interactions involving specific molecular variants in candidate genes have been identified. Replicated findings include an interaction between a polymorphism in the AKT1 gene and cannabis use in the development of psychosis and an interaction between the length polymorphism of the serotonin transporter gene and childhood maltreatment in the development of persistent depressive disorder. Bipolar disorder has been underinvestigated, with only a single study showing an interaction between a functional polymorphism in the BDNF gene and stressful life events triggering bipolar depressive episodes. The first systematic search for gene-environment interactions has found that a polymorphism in CTNNA3 may sensitize the developing brain to the pathogenic effect of cytomegalovirus in utero, leading to schizophrenia in adulthood. Strategies for genome-wide investigations will likely include coordination between epidemiological and genetic research efforts, systematic assessment of multiple environmental factors in large samples, and prioritization of genetic variants.

Keywords: gene-environment interactions, genome-wide association studies, schizophrenia, bipolar disorder, major depressive disorder, severe mental illness

\section{SEVERE MENTAL ILLNESS}

Severe mental illness (SMI) includes the most disabling psychiatric disorders that typically require inpatient treatment, such as schizophrenia, bipolar disorder, and severe depression. Family and molecular genetic studies suggest that schizophrenia, bipolar disorder, and major depressive disorder share common etiology and there may be advantages in studying these disorders jointly (1-4). This review focuses on these three disorders. Studies of subthreshold psychotic and mood symptoms are also included since they may provide additional information on etiology of SMI.

Both genetic disposition and environmental exposures play important roles in the development of SMI. The risk of SMI runs in families and is shared in proportion to the degree of biological relatedness $(5,6)$. The overall contribution of genetic factors appears to be stronger for SMI than for common mental disorders (6). Twin studies consistently estimate the heritability of schizophrenia and bipolar disorder in the range of $70-80 \%(7-9)$. The genetic contribution to depression may depend on severity: while general population-based studies find a relatively low heritability around $38 \%(10)$, the heritability of hospital-ascertained severe depression was estimated to be between 48 and 75\% (11). Molecular genetic studies have recently identified a number of specific genetic polymorphisms that directly contribute to schizophrenia, bipolar disorder, or all types of SMI across populations (12-14). The majority of the genetic variants may confer risk to more than one type of mental illness $(1,12)$.

A number of environmental factors contribute to SMI (Table 1). In utero exposure to infection, lack of nutrients, maternal stress, perinatal complications, social disadvantage, urban upbringing, ethnic minority status, childhood maltreatment, bullying, traumatic events, and cannabis use have all been found to contribute to one or more types of SMI. Some of these exposures appear to be responsible for substantial proportion of cases of SMI. For example, the availability of vitamin D during the prenatal development may be responsible for $44 \%$ cases of schizophrenia (15), childhood maltreatment and bullying account for $33 \%$ of cases of schizophrenia (16), urban birth and upbringing may be responsible for $35 \%$ of cases (17), and use of cannabis in adolescence may account for $14 \%$ of cases of schizophrenia (18). A quick addition shows that the above attributable risk percentages sum up to more than $100 \%$. This suggests that multiple factors are likely to contribute to each case of schizophrenia. Some risk factors may be correlated (e.g., a child growing up in urban setting may be more likely to be maltreated) or they may act in synergy (e.g., a person 
Table 1 | Environmental risk factors for severe mental illness

\begin{tabular}{|c|c|c|c|c|}
\hline & Exposure & Schizophrenia & Bipolar disorder & Major depressive disorder \\
\hline \multirow[t]{4}{*}{ Prenatal } & Season of birth & $+++(17)$ & $++(19)$ & $+(19)$ \\
\hline & Inadequate nutrition & $++(20)$ & $++(21)$ & $+(21)$ \\
\hline & Lead & $+(22)$ & & \\
\hline & Herpes simplex virus-2 & $++(23)$ & & \\
\hline \multirow[t]{3}{*}{ Perinatal } & Preterm birth & $++(26)$ & $+++(26)$ & $+(26)$ \\
\hline & Obstetric complications & $+(27)$ & $-(28)$ & \\
\hline & Hypoxia & & & \\
\hline \multirow[t]{3}{*}{ Childhood } & Cytomegalovirus & $+(29)$ & & \\
\hline & Urbanicity & $+++(71)$ & & \\
\hline & Minority status & $+++(41)$ & & $++(42)$ \\
\hline Adolescence & Cannabis & $+++(18)$ & $+(30)$ & $+(18)$ \\
\hline \multirow[t]{2}{*}{ Adulthood } & Stressful life events & $+(43)$ & $++(44)$ & $+++(45)$ \\
\hline & Toxoplasma & & $+(46)$ & \\
\hline
\end{tabular}

The number of plus signs indicates the strength of evidence for association: +++, consistent evidence from multiple studies or a meta-analysis; ++, evidence from several studies or a strong association in a high-quality study; +, evidence from a single study or multiple low quality studies; -, evidence for no association; blank fields reflect lack of evidence for or against association. The list is limited to environmental factors and excludes risk factors that reflect condition of the individual (e.g., birth weight).

whose early brain development was affected by a lack of vitamin $\mathrm{D}$ may be less resilient to the effects of cannabis in adolescence). Nonetheless, the high attributable risks strongly suggest that a significant proportion of cases of SMI may be preventable through modification of environment.

\section{GENE-ENVIRONIMENT INTERACTIONS}

Gene-environment interactions reflect a causal mechanism where one or more genetic variants and one or more environmental factors contribute to the causation of a condition in the same individual with the genetic factors influencing the sensitivity to environmental exposures $(47,48)$. They should be distinguished from gene-environment correlations, where genetic factors influence the probability of environmental exposures. Statistically, the likelihood of a gene-environment interaction being present is usually inferred from a significant interaction term between genetic and environmental factor in a multiple regression. Since statistical inference and power depend on the distribution of both the environmental factor and the genetic variant in a particular sample, statistical results often do not correspond to actual biological interaction $(49,50)$. Therefore, multiple methods of inquiry are required to establish whether a gene-environment interaction is involved (51).

While there are strong environmental risk factors that contribute to a large proportion of cases of SMI, there is also significant evidence of resilience and major individual differences in the impact of environmental exposures $(52,53)$. Several strong indicators suggest that the marked individual differences in sensitivity to potentially pathogenic exposures are, at least partially, due to genetic factors $(54,55)$. The combination of very high heritability and strong environmental factors suggests that a large proportion of cases of SMI must be due to a synergy between genetic and environmental causes. If a single environmental factor can explain 30 or $40 \%$ of cases of a disease that is $80 \%$ heritable, then some of the heritability must be due to joint causation by genes and environment. The way heritability is estimated in twin studies means that gene-environment interactions involving environmental factors that are shared within a family are attributed to the genetic component and contribute to heritability estimates (55-57). This misattribution of gene-environment mechanisms to heritability may account for two ostensibly paradoxical observations. First, while some of the strongest known environmental factors (e.g., urbanicity and social disadvantage) are shared within families, twin studies typically estimate no or very small contribution of shared environment (58-60). Second, since it has recently become possible to quantify the genetic contribution using molecular genetic data, it became apparent that genetic variants account for much smaller proportion of variance than the twin-based heritability estimates suggested (Figure 1). One of the most likely explanations for the heritability gap is that gene-environment interactions involving shared environmental factors are part of the twin heritability estimates but do not contribute to the molecular 


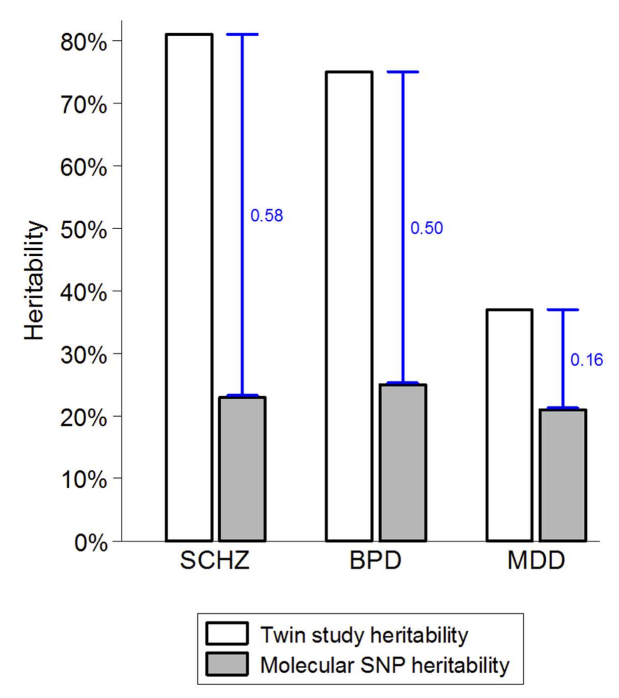

FIGURE 1 |The heritability gap. Heritability estimates from twin and molecular genetic studies for schizophrenia (SCHZ), bipolar disorder (BPD), and major depressive disorder (MDD) are based on review of twin studies and the results from the Cross-disorder Group of the Psychiatric Genetic Consortium $(1,55)$. Heritability gap is marked by a blue capped line and quantified as the proportion of total variance in the presence of each disorder. Possible explanations for the heritability gap include gene-environment interactions, inherited rare genetic variants, and overestimation of heritability in twin studies.

heritability estimates that are based on unrelated individuals (4, 55). The large "heritability gaps" for schizophrenia and bipolar disorder suggest that gene-environment interactions may potentially explain a large proportion of cases of SMI.

\section{GENE-ENVIRONMENT INTERACTIONS BY PROXY}

Several studies have attempted to estimate gene-environment interactions using the familial loading of risk for mental illness as a proxy for genetic factors. A Finnish study has shown that family history of schizophrenia interacts with low birth weight in their effect on educational achievement (61). The link between low birth weight and low educational achievement was much stronger among offspring of biological parents with schizophrenia than in children with no family history of SMI. Since low educational achievement is an antecedent to schizophrenia and major depressive disorder (62), this study may be interpreted as suggesting that gene-environment interactions operate in the early processes on the neurodevelopmental pathway to SMI. This interpretation depends on the assumption that low birth weight is a reflection of environmental factors during pregnancy. However, since a genetic contribution to birth weight is likely (63), the interpretation may become more complex. Several other studies have explored similar proxy gene-environment interactions leading to schizophrenia and other psychotic disorders. A longitudinal Finnish adoption study has shown that excellent parenting and clear communication can substantially reduce the risk of schizophrenia and related conditions among adopted offspring of biological mothers with schizophrenia while no effect of parenting was seen in adopted offspring of biological mothers without SMI (64). Another Finnish study derived data from a population-based registry and showed that serious infection during pregnancy increased the risk of psychosis in offspring who had a family history of psychotic illness (65). A large-scale Swedish adoption study has shown that socioeconomic disadvantage during upbringing increased the risk of psychosis in adoptees with a family history of SMI in biological relatives (66). Yet, the pattern is not uniform: a recent study has found a correlation between family history of psychosis and childhood maltreatment (with sons and daughters of parents with psychosis being more often maltreated by their parents), but no interaction between family history of psychosis and childhood maltreatment in the causation of psychotic disorders (67). A twin study of depression found that genetic disposition, indexed by depression in monozygotic and dizygotic co-twins, significantly interacted with environmental triggers (stressful life events) in leading to depressive episodes (68). Taken together, these studies show that pathogenic effects of many but not all environmental risk factors depend on the familial disposition to SMI. Since several of the studies were adoption or twin studies, the familial disposition was separated from the environmental factors and it can be interpreted as a proxy of genetic effects. However, even in adoption studies, there is a residual sharing of environment in the early life and in twin studies monozygotic twins may share more of their environment than dizygotic twins. Consequently, the interpretation of gene-environment studies using proxy measures is limited because familial relatedness cannot be equaled to genetic contribution and because specific environmental factors may interact with specific genetic variants rather than with the multitude of risk alleles that may constitute familial disposition. Therefore, investigation of gene-environment interactions involving specific molecular genetic variants is necessary to advance our knowledge of causal mechanisms leading to SMI.

\section{GENE-ENVIRONMENT INTERACTIONS INVOLVING SPECIFIC MOLECULAR GENETIC VARIANTS}

Molecular genetic variants can be measured with high accuracy and their identification may help the development or novel indications for therapeutics. Gene-environment interactions with specific molecular genetic variants have started to be identified in the last decade. Most of the findings have concerned communityascertained depression or other relatively common mental disorders (69). More recently, several groups of researchers have also investigated and identified specific gene-environment interactions that play a role in the causation of schizophrenia and related conditions (Table 2).

The first reported specific gene-environment interaction for a psychotic disorder included a functional polymorphism in the catechol-O-methyltransferase (COMT) gene. COMT codes an enzyme that metabolizes dopamine, the principal neuromediator involved in the positive symptoms of psychosis. A single nucleotide polymorphism (SNP) ( $\mathrm{r} 4680, \mathrm{Val}^{158} \mathrm{Met}$ ) substitutes valine by methionine (Met) at position 158, leading to the production of an enzyme that is much less efficient than the native Val variant. Caspi and colleagues found that use of cannabis in adolescence led to psychotic symptoms and disorders specifically in individuals carrying the more efficient Val alleles at the functional Val ${ }^{158} \mathrm{Met}$ COMT polymorphism (82). While the choice of candidate gene 
Table 2 | Molecular gene-environment interactions in severe mental illness.

\begin{tabular}{|c|c|c|c|c|c|}
\hline \multirow[t]{2}{*}{ Gene } & \multirow[t]{2}{*}{ Exposure } & \multirow[t]{2}{*}{ Outcome } & \multirow{2}{*}{$\begin{array}{l}\text { Original report } \\
\text { Reference }\end{array}$} & \multicolumn{2}{|r|}{ Replication } \\
\hline & & & & Result & Reference \\
\hline CRHR1 & Childhood maltreatment & Depression & Bradley et al. (72) & Yes & Polanczyk et al. (73) \\
\hline HTR2A & Parenting & Depression & Jokela et al. (74) & & \\
\hline$N R 3 C 1$ & Childhood adversity & Depression & Bet et al. (77) & & \\
\hline SLC6A4 & Childhood maltreatment & Depression & Caspi et al. (78) & Yes & Karg (79) \\
\hline SLC6A4 & Stressful life events & Depression & Caspi et al. (78) & $\mathrm{Y} / \mathrm{N}$ & $\begin{array}{l}\text { Karg et al. (79), } \\
\text { Brown et al. (80) }\end{array}$ \\
\hline$B D N F$ & Stressful life events & Bipolar depressive episodes & Hosang et al. (81) & & \\
\hline AKT1 & Cannabis & Schizophrenia/psychosis & $\begin{array}{l}\text { van Winkel and Genetic Risk and Outcome } \\
\text { of Psychosis (GROUP) Investigators (86) }\end{array}$ & Yes & di Forti et al. (87) \\
\hline$B D N F$ & Childhood maltreatment & Schizophrenia/psychosis & Alemany et al. (88) & No & Ramsay et al. (89) \\
\hline FKBP5 & Childhood maltreatment & Psychotic symptoms & Collip et al. (90) & & \\
\hline SLC6A4 & Childhood maltreatment & Cognition in psychosis & Aas et al. (91) & & \\
\hline GRIN2B & Herpes simplex virus-2 in utero & Schizophrenia/psychosis & Demontis et al. (92) & & \\
\hline CTNNA3 & Cytomegalovirus in utero & Schizophrenia/psychosis & Borglum et al. (93) & & \\
\hline
\end{tabular}

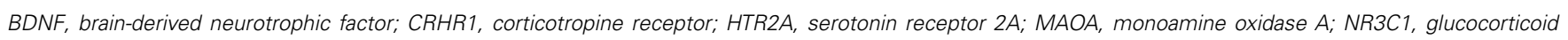

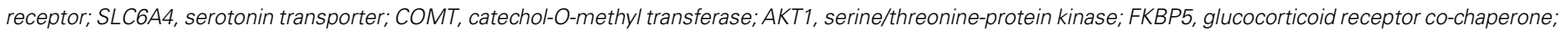
GRIN2B, glutamate NMDA receptor subunit; CTNNA3, catenin, cadherin-associated protein.

and polymorphism was well justified, the direction of the effect might have been surprising: the more efficient Val allele was associated with sensitivity whilst the less efficient Met allele conferred protection. This finding might have had major implications for personalized prevention of psychosis: a sensitizing genetic variant that explains why many young people remain well even after smoking large amounts of cannabis may help deliver a credible personalized message to those at the highest risk. However, this finding proved difficult to replicate. While initial experimental data supported the interaction (94), several independent studies reported non-replications $(83,95-97)$ or even findings in the opposite direction (98). It appeared that this gene-environment interaction must have been a false-positive finding. However, recent data suggest that there may be a genuine interaction involving COMT and cannabis. Supportive data have been reported from the genetic and psychosis (GAP) study of first onset psychosis together with an explanation why some previous studies might not have found the expected results: the pathogenic effects of cannabis depends on the proportion of tetrahydrocannabinol and cannabidiol (99, 100). When this is taken into account, the gene-environment interaction as reported by Caspi and colleagues was replicated for adolescent exposure to cannabis with high tetrahydrocannabinol to cannabidiol ratio (101). Another refinement has been reported by taking account of childhood maltreatment in addition to the use of cannabis in adolescence: Alemany and colleagues reported a three-way interaction between the COMT genotype Val alleles, childhood maltreatment, and adolescent cannabis use in the etiology of psychotic experiences (84). Most remarkably, this complex three-way interaction was independently replicated by the GROUP investigators: in their sample of Dutch young adults, combination of two COMT Val alleles childhood maltreatment and use of cannabis in adolescence was associated with the highest risk of psychotic experiences (85). While the recent refinements are awaiting further tests, the interim conclusion can be made that COMT and cannabis are likely to be part of a complex causal mechanism leading to psychotic symptoms and schizophrenia.

In the meantime, another genetic polymorphism has been identified that may moderate the effects of cannabis use in development of psychosis. This started with an investigation of 152 genetic variants in 42 selected candidate genes (86). A polymorphism (rs2494732) in the AKT1 gene was identified that interacted with the use of cannabis in the pathogenesis of psychosis: carriers of the C/C genotype on rs 2494732 were most likely to develop psychotic illness after smoking cannabis. This interaction is not just highly plausible ( $A K T 1$ codes a serine/threonine kinase that relays signal from the cannabinoid receptors), but it appears remarkably robust: the gene-environment interaction between $A K T 1$ rs2494732 and cannabis replicated across three analyses in the primary report 
(86). Soon after, an independent replication with the same direction of effect was reported in the GAP study of first-episode psychosis patients and healthy controls (87). This effect was driven by daily use of cannabis increasing the risk of psychosis sevenfold in rs2494732 C allele homozygotes, suggesting that avoidance of heavy use of cannabis is highly advisable for individuals carrying this genotype.

A group of Danish researchers focused on another established environmental risk factor for SMI: exposure to virus infection in utero (102-104). In one study, they tested 124 SNPs in five genes encoding components of the NMDA glutamatergic receptor, using 365 cases of schizophrenia and 365 matched healthy controls from the Danish population registry (92). They identified two polymorphisms (rs1805539 and rs1806205) in the GRIN2B gene that significantly interacted with maternal positivity for the herpes simplex virus-2 (92). This promising finding is awaiting a replication test.

Additional single candidate gene studies investigated genetic variants with known gene-environment interactions in common mental disorders. The FKBP5 gene coding a co-chaperone of the glucocorticoid receptor was reported to sensitize individuals to developing post-traumatic stress disorder after being exposed to childhood maltreatment (105). Collip and colleagues found a similar gene-environment interaction involving the same SNPs in FKBP5 and childhood maltreatment in increasing the risk of experiencing psychotic symptoms in young adults (90). Perhaps the most investigated gene in relationship to environment is SLC6A4, which encodes the serotonin transporter. A functional length polymorphism in the promoter of SLC6A4, known as 5-hydroxy tryptamine transporter-linked polymorphic region (5-HTTLPR), has been shown to moderate the effects of childhood maltreatment on depression: individuals carrying the short alleles of 5-HTTLPR are prone to develop persistent depressive disorder if they experience maltreatment in childhood $(78,80,106)$. Aas and colleagues investigated the interplay between 5-HTTLPR and childhood maltreatment in psychosis and found that the combination of the short 5-HTTLPR alleles and history of childhood maltreatment was associated with cognitive impairment among patients with psychotic disorders (91). This effect was only seen for physical abuse and physical neglect and it did not hold when all types of childhood maltreatment were combined. This finding is waiting for independent replication. A functional polymorphism ( $\mathrm{Val}^{66} \mathrm{Met}$ ) in the brain-derived neurotrophic factor (BDNF) gene has been reported to interact with stressful life events and childhood maltreatment in the development of depression, with Met allele carriers being more likely to develop depression after exposure to adversity (71, $107,108)$. From a convenience predominantly student sample, Alemany and colleagues have reported that BDNF Met allele carriers with a history of childhood abuse were also more likely to develop psychotic-like experiences (88); this gene-environment interaction has not been replicated in a general population sample of adolescents (89).

Compared to both major depressive disorder and schizophrenia, gene-environment interactions in bipolar disorder have been understudied. Only a single published study has reported that people with bipolar disorder who carried Met alleles at the BDNF $\mathrm{Val}^{66} \mathrm{Met}$ polymorphism were more likely to develop depressive episodes following stressful life events than Val allele homozygotes (81).

\section{SYSTEMATIC SEARCH FOR GENE-ENVIRONMENT INTERACTIONS}

All the studies reviewed above were restricted to the exploration of one or more polymorphisms in one or more genes that were selected based on their presumed functionality in relation to the disorder or the exposure of interest, i.e., they were candidate gene studies. The study of genetic associations across phenotypes has demonstrated that researchers had not been able to select the right candidate genes: most strong genetic associations turned out to be in genes that no one suspected to be involved (109). In addition, most genetic associations reported from candidate gene studies have proven to be false-positive findings perpetuated through publication bias but not replicated in large-scale systematic studies (110). While candidate gene-environment interactions have had better replicability record (Table 2) (69), the fact that study of gene-environment interactions remains largely limited to functional candidate genes is worrying. It is likely that more cases of SMI can be explained by gene-environment interactions involving genetic variants that no one had suspected than those few polymorphisms explored in the above reviewed studies. Therefore, a systematic search for gene-environment interactions across the genome is the essential next step in establishing the etiology of SMI.

To date, only one systematic search for gene-environment interactions in SMI has been carried out. A group of Danish researchers have searched the genome for genetic variants that may sensitize individuals to developing schizophrenia after being exposed to cytomegalovirus in utero (93). In 488 cases of schizophrenia and 488 healthy controls from the Danish population registry, they measured antibodies to cytomegalovirus in dried blood spots taken from infants at birth (to carry out the Guthrie test for phenylketonuria) and archived. Since the fetus does not produce its own antibodies, these antibodies are of maternal origin and a proxy of maternal infection with cytomegalovirus during pregnancy. From the same dried blood spots, they also extracted DNA and genotyped over half a million SNPs. They did not test interaction with maternal cytomegalovirus infection for all the genotyped SNPs, because of concerns about statistical power. Instead, they carried out a prioritization step and selected 29,000 polymorphisms that were significantly associated with cytomegalovirus infection in the combined case-control sample. This prioritization was based on a proposal that associations between polymorphisms and an exposure in a case-control sample may be induced by a gene-environment interaction (111) (this reasoning is only applicable to case-control samples, and only makes sense for relatively rare disorders). Among the 29,000 SNPs, the rs7902091 in the CTNNA3 gene was found to significantly interact with maternal cytomegalovirus infection in causing schizophrenia after correcting for the number of tests performed. It did not reach the accepted genome-wide level of significance. CTNNA3 encodes a cadherinassociated protein that had been liked to cardiomyopathy, but not suspected to be involved in SMI. It remains to be established whether this gene-environment interaction will prove to be robust in replication. 


\section{FUTURE OUTLOOK FOR GENES AND ENVIRONMENT}

Adequately powered genome-wide searches for gene-environment interactions should be a priority for the next decade of research. Since the statistical power for detecting gene-environment interactions is lower than statistical power for detecting direct genedisorder associations $(112,113)$, large samples will be needed. Paradoxically, these efforts are held back by the unavailability of reliably assessed environmental exposures rather than genomewide genotyping. The latest genome-wide analyses of schizophrenia, bipolar disorder, and major depressive disorder involved several tens of thousands of cases and tens of thousands of controls each. Yet the largest investigation of gene-environment interactions in schizophrenia involved fewer than 1000 cases. The situation for bipolar disorder is even more striking, with a near absence of gene-environment studies in spite of substantial shared etiology with both depression and schizophrenia and a large heritability gap left to be explained.

The move to systematic genome-wide gene-environment studies will have to overcome major challenges in addition to sample size (69). Several lines of evidence have shown that the quality of assessment of environmental variables is essential. The replicability of interaction between 5-HTTLPR and childhood maltreatment in leading to persistent depression depends on high-quality assessment of childhood maltreatment with detailed interviews or historically recorded variables (114), the replicability of interactions between COMT and cannabis use may depend on how well the exposure to cannabis is characterized, including age and frequency of use as well as the type of cannabis used $(101,115)$. In the past, large sample collection studies often discounted on the assessment quality, leading to a negative relationship between study size and quality and non-replications in large samples $(116,117)$. Therefore, when obtaining environmental variables from large samples, substantial efforts will be required to maintain the quality of assessment of environmental variables.

Another challenge lies in the selection of environmental variables to be assessed. A potentially large number of environmental exposures might be contributing to SMI (Table 1). Yet, with each environmental variable added, the number of potential geneenvironment tests increases by the number of genetic variables (which is effectively in the range of 500,000-1,000,000 after taking into account linkage disequilibrium between polymorphisms) and the sample size requirements increase accordingly.

Several initiatives have been launched with the aim to collect a systematic selection of environmental variables in addition to genetic material from moderately large samples (118120). Obtaining even larger samples would require a degree of coordination between genetic and epidemiological studies. For example, a funding agency may prioritize funding genotyping only for completely assessed samples with high-quality data on environmental exposures or support genetic sample collections in high-quality epidemiological studies of important environmental exposures. Obtaining genetic and environment data from the same rather than separate samples would create significant opportunities without increasing the total cost of research carried out. With some of these initiatives taking place, our understanding of SMI may substantially evolve over the next decade.

\section{REFERENCES}

1. Cross-Disorder Group of the Psychiatric Genomics Consortium. Genetic relationship between five psychiatric disorders estimated from genome-wide SNPs. Nat Genet (2013) 45(9):984-94. doi:10.1038/ng.2711

2. Dean K, Stevens H, Mortensen PB, Murray RM, Walsh E, Pedersen CB. Full spectrum of psychiatric outcomes among offspring with parental history of mental disorder. Arch Gen Psychiatry (2010) 67(8):822-9. doi:10.1001/ archgenpsychiatry.2010.86

3. Rasic D, Hajek T, Alda M, Uher R. Risk of mental illness in offspring of parents with schizophrenia, bipolar disorder and major depressive disorder: a meta-analysis of family high-risk studies. Schizophr Bull (2014) 40(1):28-38. doi:10.1093/schbul/sbt114

4. Uher R. Genomics and the classification of mental illness: focus on broader categories. Genome Med (2013) 5(10):97. doi:10.1186/gm501

5. Gottesman II, Laursen TM, Bertelsen A, Mortensen PB. Severe mental disorders in offspring with 2 psychiatrically ill parents. Arch Gen Psychiatry (2010) 67(3):252-7. doi:10.1001/archgenpsychiatry.2010.1

6. Shih RA, Belmonte PL, Zandi PP. A review of the evidence from family, twin and adoption studies for a genetic contribution to adult psychiatric disorders. Int Rev Psychiatry (2004) 16(4):260-83. doi:10.1080/ 09540260400014401

7. Cardno AG, Marshall EJ, Coid B, Macdonald AM, Ribchester TR, Davies NJ et al. Heritability estimates for psychotic disorders: the Maudsley twin psychosis series. Arch Gen Psychiatry (1999) 56(2):162-8. doi:10.1001/archpsyc. 56.2.162

8. Lichtenstein P, Yip BH, Bjork C, Pawitan Y, Cannon TD, Sullivan PF, et al. Common genetic determinants of schizophrenia and bipolar disorder in Swedish families: a population-based study. Lancet (2009) 373(9659):234-9. doi:10.1016/S0140-6736(09)60072-6

9. McGuffin P, Rijsdijk F, Andrew M, Sham P, Katz R, Cardno A. The heritability of bipolar affective disorder and the genetic relationship to unipolar depression. Arch Gen Psychiatry (2003) 60(5):497-502. doi:10.1001/archpsyc.60.5.497

10. Sullivan PF, Neale MC, Kendler KS. Genetic epidemiology of major depression: review and meta-analysis. Am J Psychiatry (2000) 157(10):1552-62. doi:10.1176/appi.ajp.157.10.1552

11. McGuffin P, Katz R, Watkins S, Rutherford J. A hospital-based twin register of the heritability of DSM-IV unipolar depression. Arch Gen Psychiatry (1996) 53(2):129-36. doi:10.1001/archpsyc.1996.01830020047006

12. Cross-Disorder Group of the Psychiatric Genomics Consortium. Identification of risk loci with shared effects on five major psychiatric disorders: a genomewide analysis. Lancet (2013) 381(9875):1371-9. doi:10.1016/S0140-6736(12) 62129-1

13. Green EK, Hamshere M, Forty L, Gordon-Smith K, Fraser C, Russell E, et al. Replication of bipolar disorder susceptibility alleles and identification of two novel genome-wide significant associations in a new bipolar disorder case-control sample. Mol Psychiatry (2013) 18(12):1302-7. doi:10.1038/mp. 2012.142

14. Ripke S, O’Dushlaine C, Chambert K, Moran JL, Kahler AK, Akterin S, et al. Genome-wide association analysis identifies 13 new risk loci for schizophrenia. Nat Genet (2013) 45(10):1150-9. doi:10.1038/ng.2742

15. McGrath JJ, Eyles DW, Pedersen CB, Anderson C, Ko P, Burne TH, et al. Neonatal vitamin D status and risk of schizophrenia: a population-based case-control study. Arch Gen Psychiatry (2010) 67(9):889-94. doi:10.1001/ archgenpsychiatry.2010.110

16. Varese F, Smeets F, Drukker M, Lieverse R, Lataster T, Viechtbauer W, et al. Childhood adversities increase the risk of psychosis: a meta-analysis of patientcontrol, prospective- and cross-sectional cohort studies. Schizophr Bull (2012) 38(4):661-71. doi:10.1093/schbul/sbs050

17. Mortensen PB, Pedersen CB, Westergaard T, Wohlfahrt J, Ewald H, Mors O, et al. Effects of family history and place and season of birth on the risk of schizophrenia. N Engl J Med (1999) 340(8):603-8. doi:10.1056/ NEJM199902253400803

18. Moore TH, Zammit S, Lingford-Hughes A, Barnes TR, Jones PB, Burke M, et al. Cannabis use and risk of psychotic or affective mental health outcomes: a systematic review. Lancet (2007) 370(9584):319-28. doi:10.1016/S0140-6736(07) 61162-3

19. Torrey EF, Miller J, Rawlings R, Yolken RH. Seasonality of births in schizophrenia and bipolar disorder: a review of the literature. Schizophr Res (1997) 28(1):1-38. doi:10.1016/S0920-9964(97)00092-3 
20. Susser ES, Lin SP. Schizophrenia after prenatal exposure to the Dutch hunger winter of 1944-1945. Arch Gen Psychiatry (1992) 49(12):983-8. doi:10.1001/ archpsyc.1992.01820120071010

21. Brown AS, van Os J, Driessens C, Hoek HW, Susser ES. Further evidence of relation between prenatal famine and major affective disorder. Am J Psychiatry (2000) 157(2):190-5. doi:10.1176/appi.ajp.157.2.190

22. Opler MG, Buka SL, Groeger J, McKeague I, Wei C, Factor-Litvak P, et al. Prenatal exposure to lead, delta-aminolevulinic acid, and schizophrenia: further evidence. Environ Health Perspect (2008) 116(11):1586-90. doi:10.1289/ehp. 10464

23. Buka SL, Cannon TD, Torrey EF, Yolken RH. Maternal exposure to herpes simplex virus and risk of psychosis among adult offspring. Biol Psychiatry (2008) 63(8):809-15. doi:10.1016/j.biopsych.2007.09.022

24. Brown AS, Cohen P, Harkavy-Friedman J, Babulas V, Malaspina D, Gorman JM, et al. Prenatal rubella, premorbid abnormalities, and adult schizophrenia. Biol Psychiatry (2001) 49(6):473-86. doi:10.1016/S00063223(01)01068-X

25. Khashan AS, McNamee R, Henriksen TB, Pedersen MG, Kenny LC, Abel KM, et al. Risk of affective disorders following prenatal exposure to severe life events: a Danish population-based cohort study. J Psychiatr Res (2011) 45(7):879-85. doi:10.1016/j.jpsychires.2010.12.005

26. Nosarti C, Reichenberg A, Murray RM, Cnattingius S, Lambe MP, Yin L, et al. Preterm birth and psychiatric disorders in young adult life. Arch Gen Psychiatry (2012) 69(6):E1-8. doi:10.1001/archgenpsychiatry.2011.1374

27. Cannon M, Jones PB, Murray RM. Obstetric complications and schizophrenia: historical and meta-analytic review. Am J Psychiatry (2002) 159(7):1080-92. doi:10.1176/appi.ajp.159.7.1080

28. Scott J, McNeill Y, Cavanagh J, Cannon M, Murray R. Exposure to obstetric complications and subsequent development of bipolar disorder: systematic review. Br J Psychiatry (2006) 189:3-11. doi:10.1192/bjp.bp.105.010579

29. Dalman C, Allebeck P, Gunnell D, Harrison G, Kristensson K, Lewis G, et al. Infections in the CNS during childhood and the risk of subsequent psychotic illness: a cohort study of more than one million Swedish subjects. Am J Psychiatry (2008) 165(1):59-65. doi:10.1176/appi.ajp.2007.07050740

30. Aas M, Etain B, Bellivier F, Henry C, Lagerberg T, Ringen A, et al. Additive effects of childhood abuse and cannabis abuse on clinical expressions of bipolar disorders. Psychol Med (2014) 44(8):1653-62. doi:10.1017/S0033291713002316

31. Hyun M, Friedman SD, Dunner DL. Relationship of childhood physical and sexual abuse to adult bipolar disorder. Bipolar Disord (2000) 2(2):131-5. doi:10.1034/j.1399-5618.2000.020206.x

32. Pavlova B, Uher R, Dennington L, Wright K, Donaldson C. Reactivity of affect and self-esteem during remission in bipolar affective disorder: an experimental investigation. J Affect Disord (2011) 134(1-3):102-11. doi:10.1016/j.jad.2011. 04.023

33. Lindert J, von Ehrenstein OS, Grashow R, Gal G, Braehler E, Weisskopf MG. Sexual and physical abuse in childhood is associated with depression and anxiety over the life course: systematic review and meta-analysis. Int J Public Health (2014) 59(2):359-72. doi:10.1007/s00038-013-0519-5

34. Nanni V, Uher R, Danese A. Childhood maltreatment predicts unfavorable course of illness and treatment outcome in depression: a metaanalysis. Am J Psychiatry (2012) 169(2):141-51. doi:10.1176/appi.ajp.2011. 11020335

35. Patten SB. The loss of a parent during childhood as a risk factor for depression. Can J Psychiatry (1991) 36(10):706-11.

36. Muntaner C, Eaton WW, Miech R, O'Campo P. Socioeconomic position and major mental disorders. Epidemiol Rev (2004) 26:53-62. doi:10.1093/epirev/ mxh001

37. Stilo SA, Di Forti M, Mondelli V, Falcone AM, Russo M, O’Connor J, et al. Social disadvantage: cause or consequence of impending psychosis? Schizophr Bull (2013) 39(6):1288-95. doi:10.1093/schbul/sbs112

38. Paananen R, Ristikari T, Merikukka M, Gissler M. Social determinants of mental health: a Finnish nationwide follow-up study on mental disorders. J Epidemiol Community Health (2013) 67(12):1025-31. doi:10.1136/jech-2013202768

39. Trotta A, Di Forti M, Mondelli V, Dazzan P, Pariante C, David A, et al. Prevalence of bullying victimisation amongst first-episode psychosis patients and unaffected controls. Schizophr Res (2013) 150(1):169-75. doi:10.1016/j.schres. 2013.07.001
40. Klomek AB, Sourander A, Kumpulainen K, Piha J, Tamminen T, Moilanen $\mathrm{I}$, et al. Childhood bullying as a risk for later depression and suicidal ideation among Finnish males. J Affect Disord (2008) 109(1-2):47-55. doi:10.1016/j.jad.2007.12.226

41. Fearon P, Kirkbride JB, Morgan C, Dazzan P, Morgan K, Lloyd T, et al. Incidence of schizophrenia and other psychoses in ethnic minority groups: results from the MRC AESOP study. Psychol Med (2006) 36(11):1541-50. doi:10.1017/S0033291706008774

42. Missinne S, Bracke P. Depressive symptoms among immigrants and ethnic minorities: a population based study in 23 European countries. Soc Psychiatry Psychiatr Epidemiol (2012) 47(1):97-109. doi:10.1007/s00127-010-0321-0

43. Beards S, Gayer-Anderson C, Borges S, Dewey ME, Fisher HL, Morgan C. Life events and psychosis: a review and meta-analysis. Schizophr Bull (2013) 39(4):740-7. doi:10.1093/schbul/sbt065

44. Dunner DL, Patrick V, Fieve RR. Life events at the onset of bipolar affective illness. Am J Psychiatry (1979) 136(4B):508-11.

45. Brown GW, Harris TO. Social Origins of Depression: A Study of Psychiatric Disorder in Women. London: Routledge (1978).

46. Dickerson F, Stallings C, Origoni A, Vaughan C, Katsafanas E, Khushalani S, et al. Antibodies to Toxoplasma gondii in individuals with mania. Bipolar Disord (2014) 16(2):129-36. doi:10.1111/bdi.12123

47. Rothman KJ, Greenland S, Lash TL. Modern Epidemiology. Philadelphia, PA: Wolters Kluwer Health/Lippincott Williams \& Wilkins (2008).

48. Schwartz S. Modern epidemiology approaches to interaction: application to the study of genetic interactions. In: Hernandez LM, Blazer DG, editors. Genes, Behavior, and the Social Environment: Moving Beyond the Nature/Nurture Debate. Washington, DC: National Academy of Sciences and Institute of Medicine, National Academic Press (2006). p. 310-54.

49. Rothman KJ, Greenland S. Causation and causal inference in epidemiology. Am J Public Health (2005) 95(Suppl 1):S144-50. doi:10.2105/AJPH.2004.059204

50. Uher R. Gene-environment interaction: overcoming methodological challenges. Novartis Found Symp (2008) 293:13-26.

51. Caspi A, Moffitt TE. Gene-environment interactions in psychiatry: joining forces with neuroscience. Nat Rev Neurosci (2006) 7(7):583-90. doi:10.1038/ nrn 1925

52. Collishaw S, Pickles A, Messer J, Rutter M, Shearer C, Maughan B. Resilience to adult psychopathology following childhood maltreatment: evidence from a community sample. Child Abuse Negl (2007) 31(3):211-29. doi:10.1016/j. chiabu.2007.02.004

53. Tottenham N. Risk and developmental heterogeneity in previously institutionalized children. J Adolesc Health (2012) 51(2 Suppl):S29-33. doi:10.1016/ j.jadohealth.2012.04.004

54. Uher R. Forum: the case for gene-environment interactions in psychiatry. Curr Opin Psychiatry (2008) 21(4):318-21. doi:10.1097/YCO.0b013e328306a7b9

55. Uher $\mathrm{R}$. The role of genetic variation in the causation of mental illness: an evolution-informed framework. Mol Psychiatry (2009) 14(12):1072-82. doi:10.1038/mp.2009.85

56. Susser E, Schwartz S, Morabia A, Bromet EJ. Psychiatric Epidemiology. Oxford: Oxford University Press (2006).

57. Taylor PJ. Heritability and heterogeneity: on the limited relevance of heritability in investigating genetic and environmental factors. Biol Theory (2006) 1:150-64. doi:10.1162/biot.2006.1.2.150

58. Plomin R, Asbury K, Dunn J. Why are children in the same family so different? Nonshared environment a decade later. Can J Psychiatry (2001) 46(3):225-33.

59. Taylor PJ. The unreliability of high human heritability estimates and small shared effects of growing up in the same family. Biol Theory (2008) 2:387-97. doi:10.1162/biot.2007.2.4.387

60. Turkheimer E, Waldron M. Nonshared environment: a theoretical, methodological, and quantitative review. Psychol Bull (2000) 126(1):78-108. doi:10. 1037/0033-2909.126.1.78

61. Forsyth JK, Ellman LM, Tanskanen A, Mustonen U, Huttunen MO, Suvisaari J, et al. Genetic risk for schizophrenia, obstetric complications, and adolescent school outcome: evidence for gene-environment interaction. Schizophr Bull (2013) 39(5):1067-76. doi:10.1093/schbul/sbs098

62. Koenen KC, Moffitt TE, Roberts AL, Martin LT, Kubzansky L, Harrington H, et al. Childhood IQ and adult mental disorders: a test of the cognitive reserve hypothesis. Am J Psychiatry (2009) 166(1):50-7. doi:10.1176/appi.ajp.2008. 08030343 
63. Yaghootkar H, Freathy RM. Genetic origins of low birth weight. Curr Opin Clin Nutr Metab Care (2012) 15(3):258-64. doi:10.1097/MCO.0b013e328351f543

64. Tienari P, Wynne LC, Sorri A, Lahti I, Laksy K, Moring J, et al. Genotypeenvironment interaction in schizophrenia-spectrum disorder. Long-term follow-up study of Finnish adoptees. Br J Psychiatry (2004) 184:216-22. doi:10.1192/bjp.184.3.216

65. Clarke GM, Morris AP. A comparison of sample size and power in case-only association studies of gene-environment interaction. Am J Epidemiol (2010) 171(4):498-505. doi:10.1093/aje/kwp398

66. Wicks S, Hjern A, Dalman C. Social risk or genetic liability for psychosis? A study of children born in Sweden and reared by adoptive parents. Am J Psychiatry (2010) 167(10):1240-6. doi:10.1176/appi.ajp.2010.09010114

67. Fisher HL, McGuffin P, Boydell J, Fearon P, Craig TK, Dazzan P, et al. Interplay between childhood physical abuse and familial risk in the onset of psychotic disorders. Schizophr Bull (2014). doi:10.1093/schbul/sbt201

68. Kendler KS, Kessler RC, Walters EE, MacLean C, Neale MC, Heath AC, et al. Stressful life events, genetic liability, and onset of an episode of major depression in women. Am J Psychiatry (1995) 152(6):833-42.

69. Uher R. Gene-environment interactions in common mental disorders: an update and strategy for a genome-wide search. Soc Psychiatry Psychiatr Epidemiol (2014) 49(1):3-14. doi:10.1007/s00127-013-0801-0

70. Kim JM, Stewart R, Kim SW, Yang SJ, Shin IS, Kim YH, et al. Interactions between life stressors and susceptibility genes (5-HTTLPR and BDNF) on depression in Korean elders. Biol Psychiatry (2007) 62(5):423-8. doi:10.1016/ j.biopsych.2006.11.020

71. Brown GW, Craig TKJ, Harris TO, Herbert J, Hodgson K, Tansey KE, et al. Functional polymorphism in the brain-derived neurotrophic factor gene interacts with stressful life events but not childhood maltreatment in the etiology of depression. Depress Anxiety (2014) 31(4):326-34. doi:10.1002/da.22221

72. Bradley RG, Binder EB, Epstein MP, Tang Y, Nair HP, Liu W, et al. Influence of child abuse on adult depression: moderation by the corticotropinreleasing hormone receptor gene. Arch Gen Psychiatry (2008) 65(2):190-200. doi:10.1001/archgenpsychiatry.2007.26

73. Polanczyk G, Caspi A, Williams B, Price TS, Danese A, Sugden K, et al. Protective effect of CRHR1 gene variants on the development of adult depression following childhood maltreatment: replication and extension. Arch Gen Psychiatry (2009) 66(9):978-85. doi:10.1001/archgenpsychiatry.2009.114

74. Jokela M, Keltikangas-Jarvinen L, Kivimaki M, Puttonen S, Elovainio M, Rontu $\mathrm{R}$, et al. Serotonin receptor 2A gene and the influence of childhood maternal nurturance on adulthood depressive symptoms. Arch Gen Psychiatry (2007) 64(3):356-60. doi:10.1001/archpsyc.64.3.356

75. Cicchetti D, Rogosch FA, Sturge-Apple ML. Interactions of child maltreatment and serotonin transporter and monoamine oxidase A polymorphisms: depressive symptomatology among adolescents from low socioeconomic status backgrounds. Dev Psychopathol (2007) 19(4):1161-80. doi:10.1017/ S0954579407000600

76. Melas PA, Wei Y, Wong CC, Sjoholm LK, Aberg E, Mill J, et al. Genetic and epigenetic associations of MAOA and NR3C1 with depression and childhood adversities. Int J Neuropsychopharmacol (2013) 16(7):1513-28. doi:10.1017/ S1461145713000102

77. Bet PM, Penninx BW, Bochdanovits Z, Uitterlinden AG, Beekman AT, van Schoor NM, et al. Glucocorticoid receptor gene polymorphisms and childhood adversity are associated with depression: new evidence for a gene-environment interaction. Am J Med Genet B Neuropsychiatr Genet (2009) 150B(5):660-9. doi:10.1002/ajmg.b.30886

78. Caspi A, Sugden K, Moffitt TE, Taylor A, Craig IW, Harrington H, et al. Influence of life stress on depression: moderation by a polymorphism in the 5-HTT gene. Science (2003) 301(5631):386-9. doi:10.1126/science.1083968

79. Karg K, Burmeister M, Shedden K, Sen S. The serotonin transporter promoter variant (5-HTTLPR), stress, and depression meta-analysis revisited: evidence of genetic moderation. Arch Gen Psychiatry (2011) 68(5):444-54. doi:10.1001/archgenpsychiatry.2010.189

80. Brown GW, Ban M, Craig TK, Harris TO, Herbert J, Uher R. Serotonin transporter length polymorphism, childhood maltreatment, and chronic depression: a specific gene-environment interaction. Depress Anxiety (2013) 30(1):5-13. doi:10.1002/da.21982

81. Hosang GM, Uher R, Keers R, Cohen-Woods S, Craig I, Korszun A, et al. Stressful life events and the brain-derived neurotrophic factor gene in bipolar disorder. J Affect Disord (2010) 125(1-3):345-9. doi:10.1016/j.jad.2010.01.071
82. Caspi A, Moffitt TE, Cannon M, McClay J, Murray R, Harrington H, et al. Moderation of the effect of adolescent-onset cannabis use on adult psychosis by a functional polymorphism in the catechol-O-methyltransferase gene: longitudinal evidence of a gene $\mathrm{X}$ environment interaction. Biol Psychiatry (2005) 57(10):1117-27. doi:10.1016/j.biopsych.2005.01.026

83. Zammit S, Spurlock G, Williams H, Norton N, Williams N, O'Donovan MC, et al. Genotype effects of CHRNA7, CNR1 and COMT in schizophrenia: interactions with tobacco and cannabis use. Br J Psychiatry (2007) 191:402-7. doi:10.1192/bjp.bp.107.036129

84. Alemany S, Arias B, Fatjo-Vilas M, Villa H, Moya J, Ibanez MI, et al. Psychosis-inducing effects of cannabis are related to both childhood abuse and COMT genotypes. Acta Psychiatr Scand (2014) 129(1):54-62. doi:10.1111/ acps. 12108

85. Vinkers CH, van Gastel WA, Schubart CD, Van Eijk KR, Luykx JJ, van WR, et al. The effect of childhood maltreatment and cannabis use on adult psychotic symptoms is modified by the COMT Val(1)(5)(8)Met polymorphism. Schizophr Res (2013) 150(1):303-11. doi:10.1016/j.schres.2013.07.020

86. van Winkel R; Genetic Risk and Outcome of Psychosis (GROUP) Investigators. Family-based analysis of genetic variation underlying psychosis-inducing effects of cannabis: sibling analysis and proband follow-up. Arch Gen Psychiatry (2011) 68(2):148-57. doi:10.1001/archgenpsychiatry.2010.152

87. Di Forti M, Iyegbe C, Sallis H, Kolliakou A, Falcone MA, Paparelli A, et al. Confirmation that the AKT1 (rs2494732) genotype influences the risk of psychosis in cannabis users. Biol Psychiatry (2012) 72(10):811-6. doi:10.1016/j.biopsych. 2012.06.020

88. Alemany S, Arias B, Aguilera M, Villa H, Moya J, Ibanez MI, et al. Childhood abuse, the BDNF-Val66Met polymorphism and adult psychotic-like experiences. Br J Psychiatry (2011) 199(1):38-42. doi:10.1192/bjp.bp.110.083808

89. Ramsay H, Kelleher I, Flannery P, Clarke MC, Lynch F, Harley M, et al. Relationship between the COMT-Val158Met and BDNF-Val66Met polymorphisms, childhood trauma and psychotic experiences in an adolescent general population sample. PLoS One (2013) 8(11):e79741. doi:10.1371/journal.pone. 0079741

90. Collip D, Myin-Germeys I, Wichers M, Jacobs N, Derom C, Thiery E, et al. FKBP5 as a possible moderator of the psychosis-inducing effects of childhood trauma. Br J Psychiatry (2013) 202(4):261-8. doi:10.1192/bjp.bp. 112.115972

91. Aas M, Djurovic S, Athanasiu L, Steen NE, Agartz I, Lorentzen S, et al. Serotonin transporter gene polymorphism, childhood trauma, and cognition in patients with psychotic disorders. Schizophr Bull (2012) 38(1):15-22. doi:10.1093/schbul/sbr113

92. Demontis D, Nyegaard M, Buttenschon HN, Hedemand A, Pedersen CB, Grove J, et al. Association of GRIN1 and GRIN2A-D with schizophrenia and genetic interaction with maternal herpes simplex virus-2 infection affecting disease risk. Am J Med Genet B Neuropsychiatr Genet (2011) 156B(8):913-22. doi:10.1002/ajmg.b.31234

93. Borglum AD, Demontis D, Grove J, Pallesen J, Hollegaard MV, Pedersen $\mathrm{CB}$, et al. Genome-wide study of association and interaction with maternal cytomegalovirus infection suggests new schizophrenia loci. Mol Psychiatry (2013) 19(3):325-33. doi:10.1038/mp.2013.2

94. Henquet C, Rosa A, Krabbendam L, Papiol S, Fananas L, Drukker M, et al. An experimental study of catechol-O-methyltransferase Val158Met moderation of delta-9-tetrahydrocannabinol-induced effects on psychosis and cognition. Neuropsychopharmacology (2006) 31(12):2748-57. doi:10.1038/sj.npp. 1301197

95. De Sousa KR, Tiwari AK, Giuffra DE, Mackenzie B, Zai CC, Kennedy JL. Age at onset of schizophrenia: cannabis, COMT gene, and their interactions. Schizophr Res (2013) 151(1-3):289-90. doi:10.1016/j.schres.2013.10.037

96. Kantrowitz JT, Nolan KA, Sen S, Simen AA, Lachman HM, Bowers MB Jr. Adolescent cannabis use, psychosis and catechol-O-methyltransferase genotype in African Americans and Caucasians. Psychiatr Q (2009) 80(4):213-8. doi:10.1007/s11126-009-9108-4

97. Zammit S, Owen MJ, Evans J, Heron J, Lewis G. Cannabis, COMT and psychotic experiences. Br J Psychiatry (2011) 199(5):380-5. doi:10.1192/bjp.bp. 111.091421

98. Costas J, Sanjuan J, Ramos-Rios R, Paz E, Agra S, Tolosa A, et al. Interaction between COMT haplotypes and cannabis in schizophrenia: a caseonly study in two samples from Spain. Schizophr Res (2011) 127(1-3):22-7. doi:10.1016/j.schres.2011.01.014 
99. Niesink RJ, van Laar MW. Does cannabidiol protect against adverse psychological effects of THC? Front Psychiatry (2013) 4:130. doi:10.3389/fpsyt.2013.00130

100. Schubart CD, Sommer IE, van Gastel WA, Goetgebuer RL, Kahn RS, Boks MP. Cannabis with high cannabidiol content is associated with fewer psychotic experiences. Schizophr Res (2011) 130(1-3):216-21. doi:10.1016/j.schres.2011. 04.017

101. Murray RM, Di Forti M. Confirmation that the AKT1 (RS 2494732) genotype influences the risk of psychosis in cannabis users. 68th Annual Scientific Meeting of the Society-of-Biological-Psychiatry, San Francisco (2013).

102. Brown AS. The environment and susceptibility to schizophrenia. Prog Neurobiol (2011) 93(1):23-58. doi:10.1016/j.pneurobio.2010.09.003

103. Buka SL, Tsuang MT, Torrey EF, Klebanoff MA, Bernstein D, Yolken RH. Maternal infections and subsequent psychosis among offspring. Arch Gen Psychiatry (2001) 58(11):1032-7. doi:10.1001/archpsyc.58.11.1032

104. Khandaker GM, Zimbron J, Lewis G, Jones PB. Prenatal maternal infection, neurodevelopment and adult schizophrenia: a systematic review of population-based studies. Psychol Med (2013) 43(2):239-57. doi:10.1017/ S0033291712000736

105. Binder EB, Bradley RG, Liu W, Epstein MP, Deveau TC, Mercer KB, et al. Association of FKBP5 polymorphisms and childhood abuse with risk of posttraumatic stress disorder symptoms in adults. JAMA (2008) 299(11):1291-305. doi:10.1001/jama.299.11.1291

106. Uher R, Caspi A, Houts R, Sugden K, Williams B, Poulton R, et al. Serotonin transporter gene moderates childhood maltreatment's effects on persistent but not single-episode depression: replications and implications for resolving inconsistent results. J Affect Disord (2011) 135(1-3):56-65. doi:10.1016/j.jad. 2011.03.010

107. Carver CS, Johnson SL, Joormann J, Lemoult J, Cuccaro ML. Childhood adversity interacts separately with 5-HTTLPR and BDNF to predict lifetime depression diagnosis. J Affect Disord (2011) 132(1-2):89-93. doi:10.1016/j.jad.2011. 02.001

108. Hosang GM, Shiles C, Tansey KE, McGuffin P, Uher R. Interaction between stress and the BDNF Val66Met polymorphism in depression: a systematic review and meta-analysis. BMC Med (2014) 12:7. doi:10.1186/1741-7015-12-7

109. Collins AL, Kim Y, Sklar P, O’Donovan MC, Sullivan PF. Hypothesis-driven candidate genes for schizophrenia compared to genome-wide association results. Psychol Med (2012) 42(3):607-16. doi:10.1017/S0033291711001607

110. Sanders AR, Duan J, Levinson DF, Shi J, He D, Hou C, et al. No significant association of 14 candidate genes with schizophrenia in a large European ancestry sample: implications for psychiatric genetics. Am J Psychiatry (2008) 165(4):497-506. doi:10.1176/appi.ajp.2007.07101573

111. Murcray CE, Lewinger JP, Gauderman WJ. Gene-environment interaction in genome-wide association studies. Am J Epidemiol (2009) 169(2):219-26. doi:10.1093/aje/kwn353

112. Caspi A, Hariri AR, Holmes A, Uher R, Moffitt TE. Genetic sensitivity to the environment: the case of the serotonin transporter gene and its implications for studying complex diseases and traits. Am J Psychiatry (2010) 167(5):509-27. doi:10.1176/appi.ajp.2010.09101452
113. McClelland GH, Judd CM. Statistical difficulties of detecting interactions and moderator effects. Psychol Bull (1993) 114(2):376-90. doi:10.1037/0033-2909. 114.2.376

114. Uher R, McGuffin P. The moderation by the serotonin transporter gene of environmental adversity in the etiology of depression: 2009 update. Mol Psychiatry (2010) 15(1):18-22. doi:10.1038/mp.2009.123

115. Di Forti M, Sallis H, Allegri F, Trotta A, Ferraro L, Stilo SA, et al. Daily use, especially of high-potency cannabis, drives the earlier onset of psychosis in cannabis users. Schizophr Bull (2014). doi:10.1093/schbul/sbt181

116. Monroe SM, Reid MW. Gene-environment interactions in depression research: genetic polymorphisms and life-stress polyprocedures. Psychol Sci (2008) 19(10):947-56. doi:10.1111/j.1467-9280.2008.02181.x

117. Uher R, McGuffin P. The moderation by the serotonin transporter gene of environmental adversity in the aetiology of mental illness: review and methodological analysis. Mol Psychiatry (2008) 13(2):131-46. doi:10.1038/sj. mp.4002067

118. Costello EJ, Eaves L, Sullivan P, Kennedy M, Conway K, Adkins DE, et al. Genes, environments, and developmental research: methods for a multi-site study of early substance abuse. Twin Res Hum Genet (2013) 16(2):505-15. doi:10.1017/thg.2013.6

119. Korver N, Quee PJ, Boos HB, Simons CJ, de Haan L; GROUP Investigators. Genetic Risk and Outcome of Psychosis (GROUP), a multi site longitudinal cohort study focused on gene-environment interaction: objectives, sample characteristics, recruitment and assessment methods. Int J Methods Psychiatr Res (2012) 21(3):205-21. doi:10.1002/mpr.1352

120. Navarro-Mateu F, Tormo M, Vilagut G, Alonso J, Ruiz-Merino G, Escamez T, et al. Epidemiology and genetics of common mental disorders in the general population: the PEGASUS-Murcia project. BMJ Open (2013) 3(12):e004035. doi:10.1136/bmjopen-2013-004035

Conflict of Interest Statement: The author declares that the research was conducted in the absence of any commercial or financial relationships that could be construed as a potential conflict of interest. The Guest Associate Editor Helen Fisher declares that, despite having collaborated with the author Rudolf Uher, the review process was handled objectively.

Received: 18 January 2014; paper pending published: 12 February 2014; accepted: 23 April 2014; published online: 15 May 2014.

Citation: Uher R (2014) Gene-environment interactions in severe mental illness. Front. Psychiatry 5:48. doi: 10.3389/fpsyt.2014.00048

This article was submitted to Schizophrenia, a section of the journal Frontiers in Psychiatry.

Copyright (c) 2014 Uher. This is an open-access article distributed under the terms of the Creative Commons Attribution License (CC BY). The use, distribution or reproduction in other forums is permitted, provided the original author(s) or licensor are credited and that the original publication in this journal is cited, in accordance with accepted academic practice. No use, distribution or reproduction is permitted which does not comply with these terms. 